\title{
Causes of Spinal Cord Injury
}

\author{
Yuying Chen, MD, PhD, ${ }^{1}$ Ying Tang, $M S,{ }^{2}$ Lawrence C. Vogel, MD, ${ }^{3,4}$ and Michael J. DeVivo, DrPH \\ ${ }^{1}$ Department of Physical Medicine and Rehabilitation, ${ }^{2}$ Department of Biostatistics, University of Alabama at Birmingham, \\ Birmingham, Alabama; ${ }^{3}$ Rush Medical College, Chicago, Illinois; ${ }^{4}$ Shriners Hospitals for Children, Chicago, Illinois
}

\begin{abstract}
Background: Knowledge of the causes of spinal cord injury (SCI) and associated factors is critical in the development of successful prevention programs. Objective: This study analyzed data from the National SCI Database (NSCID) and National Shriners SCI Database (NSSCID) in the United States to examine specific etiologies of SCI by age, sex, race, ethnicity, day and month of injury, and neurologic outcomes. Methods: NSCID and NSSCID participants who had a traumatic SCI from 2005 to 2011 with known etiology were included in the analyses $(N=7,834)$. Thirty-seven causes of injury documented in the databases were stratified by personal characteristics using descriptive analysis. Results: The most common causes of SCl were automobile crashes $(31.5 \%)$ and falls $(25.3 \%)$, followed by gunshot wounds (10.4\%), motorcycle crashes $(6.8 \%)$, diving incidents $(4.7 \%)$, and medical/surgical complications (4.3\%), which collectively accounted for $83.1 \%$ of total SCls since 2005 . Automobile crashes were the leading cause of $\mathrm{SCl}$ until age 45 years, whereas falls were the leading cause after age 45 years. Gunshot wounds, motorcycle crashes, and diving caused more SCls in males than females. The major difference among race/ethnicity was in the proportion of gunshot wounds. More SCls occurred during the weekends and warmer months, which seemed to parallel the increase of motorcycle- and diving-related SCls. Level and completeness of injury are also associated with etiology of injury. Conclusions: The present findings suggest that prevention strategies should be tailored to the targeted population and major causes to have a meaningful impact on reducing the incidence of $\mathrm{SCl}$. Key words: epidemiology, etiology, prevention, spinal cord injuries
\end{abstract}

$\mathrm{S}$ pinal cord injury (SCI) is not as common as many other injuries, yet its physical and psychosocial consequences are devastating. Very few people experience complete neurologic recovery after SCI. ${ }^{1,2}$ A significant proportion of SCIs result in neurologically complete and tetraplegic deficits. Lifetime costs of managing SCI and related secondary conditions are staggering and pose a significant burden to individuals with SCI, their families, and society. ${ }^{3,4}$ Hence, given the immense personal and financial burdens of SCI, prevention is critical.

Primary prevention of SCI is currently a global effort. For example, the International Spinal Cord Society (ISCoS) recently launched a global mapping project that provides a structure for an ongoing data repository to inform stakeholders of the development and coordination of prevention strategies. ${ }^{5}$ The reported SCI incidence rate in the United States (39 per million) is close to Canada (35 per million), but it is considerately higher than the figures reported in Western Europe (16 per million) and Australia (15 per million). In addition to differences in methodology, population characteristics, and pre-hospital mortality rates, the increase of SCI incidence in the North America seems to be associated with a higher percentage of violence-related SCIs (18\%) compared to Western Europe (8\%) and Australia (2\%). ${ }^{5}$
Within the United States, SCI incidence differs geographically. Data from the state SCI registries in the 1980s and 1990s showed that the annual rates (per million) were 25 new cases in West Virginia, ${ }^{6}$ 28 in Arkansas, ${ }^{7} 30$ in Virginia, ${ }^{8} 39$ in Utah, ${ }^{9} 40$ in Oklahoma, ${ }^{10} 43$ in New York, ${ }^{11} 45$ in Colorado, ${ }^{12}$ 46 in Louisiana, ${ }^{13} 46$ in Georgia, ${ }^{14} 56$ in Rhode Island, ${ }^{15} 59$ in Mississippi, ${ }^{16}$ and 83 in Alaska. ${ }^{17}$

There are no recent population-based studies that support an increase or decrease in SCI incidence in the United States. Study findings from the National SCI Database (NSCID), however, suggest a changing injury profile over time. ${ }^{18,19}$ The percentage of SCIs due to falls has steadily increased over the last 4 decades, from $17 \%$ in the 1970 s to $28 \%$ in 2005 to 2011 . The percentage of SCIs due to violence increased substantially between 1973 and 1999 (up to 29\%), but significantly dropped after 2000 (14\%). Sports and recreational activities as the cause of SCI continuously declined for about 30 years and then stayed steady over the last 10 years, from $14 \%$ in the 1970 s to $8 \%$ in 2005 to 2011. Motor vehicle crashes have consistently

Top Spinal Cord Inj Rehabil 2013;19(1):1-8

(c) 2013 Thomas Land Publishers, Inc.

www.thomasland.com

doi: $10.1310 /$ sci1901-1 
been the leading cause of SCI over the last 40 years, accounting for about $40 \%$ to $50 \%$ of all SCIs reported to the NSCID.

Utilizing data from the NSCID and the comparable National Shriners SCI Database (NSSCID) since 2005, this article analyzes specific causes of SCI, rather than the grouped etiologies that have been widely reported in previous investigations. The etiology of SCI is analyzed with respect to age, gender, race/ethnicity, day of the week, month of the year, and neurological level and severity. This information is critical in order to identify specific target populations and risk behaviors for prevention, evaluate the relevance of any ongoing prevention strategies, and determine the needs for health services and care for SCI.

\section{Methods}

\section{Data sources}

The NSCID began in 1973 and is believed to capture data from approximately $13 \%$ to $15 \%$ of new SCIs every year in the United States. Since its inception, 28 federally funded SCI Model System centers have contributed data to NSCID, including demographics, injury and medical characteristics, and functional independence during the initial hospitalization and at postinjury years 1 and 5 and every 5 years thereafter. ${ }^{20}$ Psychosocial outcomes and assistive technology information have also been obtained at each follow-up. The NSCID defines SCI as the occurrence of an acute traumatic lesion of neural elements in the spinal canal, resulting in temporary or permanent sensory and/or motor deficit. The clinical definition of SCI excludes intervertebral disc disease, vertebral injuries in the absence of SCI, nerve root avulsions and injuries to nerve roots and peripheral nerves outside the spinal canal, cancer, spinal cord vascular disease, and other nontraumatic spinal cord diseases. Details about this database have been described elsewhere. ${ }^{21}$ A parallel NSSCID that enrolls children with SCI who received care from the 3 SCI units of the Shriners Hospital for Children in Sacramento, California; Chicago, Illinois; and Philadelphia, Pennsylvania was established in 1987. Data have been collected prospectively since 1987 using the same protocol as the NSCID. ${ }^{22}$ The vast majority of children enrolled in the NSSCID are from the United States.

\section{Study participants}

The present analyses are limited to persons enrolled in the NSCID and NSSCID who sustained a traumatic SCI between 2005 and $2011(\mathrm{~N}=7,882)$. After excluding those with unknown etiology of injury $(n=48)$, a total of 7,429 persons from 19 SCI Model System Centers and 405 persons from the 3 Shriners SCI units were included in this study. The participating SCI Model System centers and corresponding sample size are as follows: Alabama $(\mathrm{n}=432)$, California $(\mathrm{n}=76$, from 2 centers), Colorado $(n=946)$, District of Columbia $(n=197)$, Florida $(n=41)$, Georgia $(n=1,907)$, Illinois $(n=350)$, Massachusetts $(n=232)$, Michigan $(\mathrm{n}=243)$, Missouri $(\mathrm{n}=34)$, New York $(\mathrm{n}=286)$, New Jersey $(n=485)$, Ohio $(n=265)$, Pennsylvania $(\mathrm{n}=968$, from 2 centers), Texas $(\mathrm{n}=482)$, Virginia $(n=29)$, and Washington $(n=456)$. Table 1 shows the participants' characteristics.

\section{Variables, measures, and grouping}

Demographic and injury characteristics were collected by trained personnel at each hospital using a standardized protocol during initial hospital care. Age at injury, sex, race, ethnicity, and etiology of injury were obtained either from the hospital admission record or by personal interview. Neurological examinations were performed by physicians or specially trained nurses or physical/ occupational therapists in accordance with the version of the International Standards for Neurological Classification of SCI that was in use at the time the examinations were performed. ${ }^{23}$ Additional data collection procedures as well as forms and instructions are available on the NSCISC Web site (https://www.nscis.uab.edu/).

\section{Statistical analysis}

Frequency and percentage were used to describe the most common specific causes of SCI by age, sex, and race/ethnicity. The month and day of injury as well as neurological outcomes were also examined by injury etiologies. All data were 
Table 1. Demographic and injury profile of study participants $(\mathrm{N}=7,834)$

\begin{tabular}{|c|c|c|}
\hline Characteristics & $\mathbf{n}$ & $(\%)$ \\
\hline \multicolumn{3}{|l|}{ Age group, years } \\
\hline $0-15$ & 384 & $(4.9)$ \\
\hline $16-30$ & 3,015 & $(38.5)$ \\
\hline $31-45$ & 1,645 & $(21.0)$ \\
\hline $46-60$ & 1,686 & $(21.5)$ \\
\hline 61 and above & 1,103 & $(14.1)$ \\
\hline Unknown & 1 & - \\
\hline \multicolumn{3}{|l|}{ Sex } \\
\hline Male & 6,132 & $(78.3)$ \\
\hline Female & 1,700 & $(21.7)$ \\
\hline Unknown & 2 & - \\
\hline \multicolumn{3}{|l|}{ Race } \\
\hline White, Non-Hispanic & 5,051 & $(66.8)$ \\
\hline Black, Non-Hispanic & 1,562 & $(20.7)$ \\
\hline Hispanic & 692 & $(9.2)$ \\
\hline Other & 252 & $(3.3)$ \\
\hline Unknown & 277 & - \\
\hline \multicolumn{3}{|l|}{ Level of injury } \\
\hline $\mathrm{C} 1-\mathrm{C} 4$ & 2,323 & $(30.6)$ \\
\hline $\mathrm{C} 5-\mathrm{C} 8$ & 2,091 & $(27.6)$ \\
\hline T1-T6 & 1,147 & $(15.1)$ \\
\hline T7-S3 & 1,965 & $(25.9)$ \\
\hline Normal & 55 & $(0.7)$ \\
\hline Unknown & 253 & - \\
\hline \multicolumn{3}{|c|}{ Completeness of injury (AIS) } \\
\hline A & 3,300 & $(43.6)$ \\
\hline $\mathrm{B}$ & 1,011 & $(13.4)$ \\
\hline $\mathrm{C}$ & 1,177 & $(15.6)$ \\
\hline $\mathrm{D}$ & 2,032 & $(26.9)$ \\
\hline $\mathrm{E}$ & 46 & $(0.6)$ \\
\hline Unknown & 268 & - \\
\hline \multicolumn{3}{|l|}{ Day of injury } \\
\hline Monday & 1,004 & $(12.8)$ \\
\hline Tuesday & 916 & (11.7) \\
\hline Wednesday & 976 & (12.5) \\
\hline Thursday & 979 & (12.5) \\
\hline Friday & 1,118 & (14.3) \\
\hline Saturday & 1,483 & (18.9) \\
\hline Sunday & 1,358 & $(17.3)$ \\
\hline \multicolumn{3}{|l|}{ Month of injury } \\
\hline January & 589 & $(7.5)$ \\
\hline February & 490 & $(6.3)$ \\
\hline March & 697 & $(8.9)$ \\
\hline April & 672 & $(8.6)$ \\
\hline May & 750 & $(9.6)$ \\
\hline June & 740 & $(9.5)$ \\
\hline July & 851 & (10.9) \\
\hline August & 715 & $(9.1)$ \\
\hline September & 635 & $(8.1)$ \\
\hline October & 585 & $(7.5)$ \\
\hline November & 555 & $(7.1)$ \\
\hline December & 555 & (7.1) \\
\hline
\end{tabular}

Note: AIS = American Spinal Injury Association Impairment Scale. analyzed and reported in compliance with the International Analytic Standard, as appropriate. ${ }^{24}$

\section{Results}

The NSCID and NSSCID document 37 causes of injury (Table 2). The most common etiologies of SCI were automobile crashes (31.5\%) and falls (25.3\%), followed by gunshot wounds (10.4\%), motorcycle crashes $(6.8 \%)$, diving incidents $(4.7 \%)$, and medical/surgical complications $(4.3 \%)$. These 6 causes collectively accounted for $83.1 \%$ of total SCIs reported to the NSCID and NSSCID since 2005.

The most common age of injury was between the ages of 16 and 30 years $(38.5 \%)$, followed by ages 31 to 45 and 46 to 60 years $(21.0 \%$ and $21.5 \%$, respectively; Table 1 ). The etiology profile varied substantially by age (Table 3 ). Automobile crashes were the leading cause of SCI until age 45 years and then dropped to number 2, whereas falls were the leading cause after age 45 years. In fact, falls accounted for about $75 \%$ of all SCIs among persons 76 years of age and older. Gunshot wounds were the second leading cause for persons aged 16 to 30 years $(19.0 \%)$ and the third most common cause for those 0 to 15 years old $(8.1 \%)$, but this etiology declined rapidly with advancing age. Motorcycle crashes ranked third for persons 31 to 45 and 46 to 60 years of age (10.9\% and $7.1 \%$, respectively). Medical/surgical complications were the second leading cause for children younger than 16 years $(12.8 \%)$ and the third leading cause for persons older than 60 years (10.9\%).

Overall, $78.3 \%$ of all reported SCIs occurred among males (Table 1). The first 2 leading causes, automobile crashes and falls, collectively accounted for $53.5 \%$ of all SCIs in males and $68.6 \%$ in females (Table 4). Gunshot wounds, motorcycle crashes, and diving caused more SCIs in males than females $(11.7 \%$ vs $5.8 \%, 8.0 \%$ vs $2.4 \%$, and $5.3 \%$ vs $2.4 \%$, respectively). In contrast, medical/ surgical complications ranked number 6 for males, but were the third leading cause for females (3.3\% vs $7.6 \%)$. The major difference in etiology profile among the race/ethnicity group was in the proportion of gunshot wounds that caused 33.0\% of all SCIs in blacks, $14.6 \%$ in Hispanics, $9.5 \%$ in other races, but only $3.0 \%$ in whites. 
Table 2. Specific etiology of spinal cord injury, 2005-2011

\begin{tabular}{|c|c|c|c|}
\hline Rank & Specific etiology & n & $(\%)$ \\
\hline 1 & Auto crash, including jeep, truck, dune buggy, and bus & 2,465 & $(31.47)$ \\
\hline 2 & Fall, including jumping and being pushed accidentally (not as an act of violence) & 1,981 & $(25.29)$ \\
\hline 3 & Gunshot wound & 816 & $(10.42)$ \\
\hline 4 & Motorcycle crash: 2-wheeled, motorized vehicles including mopeds and motorized dirt bikes & 533 & $(6.80)$ \\
\hline 5 & Diving & 366 & $(4.67)$ \\
\hline 6 & $\begin{array}{l}\text { Medical/surgical complications: impairment of spinal cord function resulting from adverse effects of medical, surgical } \\
\text { or diagnostic procedures and treatment }\end{array}$ & 333 & $(4.25)$ \\
\hline 7 & Hit by falling/flying object, including ditch cave in, avalanche, rockslide & 177 & $(2.26)$ \\
\hline 8 & Bicycle, tricycles, and unicycles & 166 & $(2.12)$ \\
\hline 9 & All-terrain vehicle and cycle (ATV/ATC): 3-wheeled and 4-wheeled & 140 & $(1.79)$ \\
\hline 10 & Pedestrian, including falling/jumping into the path of a vehicle & 100 & $(1.28)$ \\
\hline 11 & $\begin{array}{l}\text { Other sport: auto racing, glider kite, slide, swimming, bungee jumping, scuba diving, roller blading, jet-skiing, } \\
\text { cheerleading, etc }\end{array}$ & 82 & $(1.05)$ \\
\hline 12 & Other unclassified: lightning, kicked by an animal, machinery accidents & 76 & $(0.97)$ \\
\hline 13 & Other vehicular: tractor, bulldozer, go-cart, steamroller, train, road grader, forklift, etc & 71 & $(0.91)$ \\
\hline 14 & Winter sports: sledding, snow tubing, tobogganing, playing ice hockey, snowboarding, etc & 67 & $(0.86)$ \\
\hline 15 & Personal contact, including being hit with a blunt object, falls as a result of being pushed (as an act of violence) & 60 & $(0.77)$ \\
\hline 16 & Surfing, including body surfing & 60 & $(0.77)$ \\
\hline 17 & Snow skiing & 55 & $(0.70)$ \\
\hline 18 & Horseback riding & 54 & $(0.69)$ \\
\hline 19 & Football & 35 & $(0.45)$ \\
\hline 20 & Wrestling & 26 & $(0.33)$ \\
\hline 21 & Other penetrating wounds: stabbing, impalement, etc & 25 & $(0.32)$ \\
\hline 22 & Fixed-wing aircraft & 24 & $(0.31)$ \\
\hline 23 & Snowmobile & 20 & $(0.26)$ \\
\hline 24 & Boat & 14 & $(0.18)$ \\
\hline 25 & Air sports: parachuting, para-sailing, etc & 12 & $(0.15)$ \\
\hline 26 & Gymnastic activities other than trampoline & 12 & $(0.15)$ \\
\hline 27 & Trampoline & 11 & $(0.14)$ \\
\hline 28 & Rodeo, including bronco/bull riding & 10 & $(0.13)$ \\
\hline 29 & Field sports: field hockey, lacrosse, soccer, rugby, etc & 8 & $(0.10)$ \\
\hline 30 & Rotating wing aircraft & 7 & $(0.09)$ \\
\hline 31 & Baseball/softball & 6 & $(0.08)$ \\
\hline 32 & Water skiing & 6 & $(0.08)$ \\
\hline 33 & Basketball/volleyball & 5 & $(0.06)$ \\
\hline 34 & Hang gliding & 4 & $(0.05)$ \\
\hline 35 & Skateboard & 3 & $(0.04)$ \\
\hline 36 & Track and field: pole vault, high jump, etc & 3 & $(0.04)$ \\
\hline 37 & Explosion: bomb, grenade, dynamite, and gasoline & 1 & $(0.01)$ \\
\hline
\end{tabular}

More SCIs occurred on Saturday (18.9\%) and Sunday (17.3\%) than on any other day (Table 1), which was likely explained by a higher number of SCIs as a result of motorcycle crashes and diving incidents during the weekends (Table 5). On the contrary, fewer SCIs as a result of medical/surgical complications occurred on Saturday and Sunday (6.3\% and $5.4 \%$, respectively) than on Monday and Tuesday (19.8\% and $21.0 \%$, respectively). SCI seems to occur in cycles. The fewest SCIs occur in February $(6.3 \%)$; they steadily increase until July $(10.9 \%)$ and then steadily decline until the next February. This seasonal variation seemed to parallel the increase in motorcycle- and divingrelated SCIs that occur in the warmer months.

Level and completeness of injury is associated with etiology of injury (Table 6). Gunshot wounds and medical/surgical complications typically resulted in paraplegia, especially $\mathrm{T} 7-\mathrm{S} 3$ ( $45.9 \%$ and $43.7 \%$, respectively). Diving injury, in contrast, almost always resulted in tetraplegia (44.0\% C1-C4 and $52.4 \%$ C5-C8). A substantial number of falls and medical/surgical complications resulted in functional motor incomplete injuries (American Spinal Injury Association Impairment Scale [AIS] D, $39.7 \%$ and $40.8 \%$, respectively). The majority 
Table 3. Top 10 specific etiologies of spinal cord injury by age

\begin{tabular}{|c|c|c|c|c|c|c|c|c|c|c|}
\hline \multirow[b]{3}{*}{ Etiology } & \multicolumn{10}{|c|}{ Age group, years } \\
\hline & \multicolumn{2}{|c|}{$\begin{array}{c}0-15 \\
(n=384)\end{array}$} & \multicolumn{2}{|c|}{$\begin{array}{c}16-30 \\
(n=3,015)\end{array}$} & \multicolumn{2}{|c|}{$\begin{array}{c}31-45 \\
(n=1,645) \\
\end{array}$} & \multicolumn{2}{|c|}{$\begin{array}{c}46-60 \\
(n=1,686)\end{array}$} & \multicolumn{2}{|c|}{$\begin{array}{c}61 \& \text { above } \\
(n=1,103)\end{array}$} \\
\hline & Rank & $(\%)$ & Rank & $(\%)$ & Rank & $(\%)$ & Rank & $(\%)$ & Rank & $(\%)$ \\
\hline Automobile & 1 & $(40.1)$ & 1 & $(38.4)$ & 1 & $(32.2)$ & 2 & $(25.6)$ & 2 & (17.4) \\
\hline Fall & 4 & $(7.6)$ & 3 & $(10.0)$ & 2 & $(23.0)$ & 1 & $(38.4)$ & 1 & (56.8) \\
\hline Gunshot & 3 & $(8.1)$ & 2 & $(19.0)$ & 4 & $(9.7)$ & 7 & $(2.7)$ & 10 & $(0.7)$ \\
\hline Motorcycle & 9 & $(2.3)$ & 5 & $(6.6)$ & 3 & (10.9) & 3 & (7.1) & 4 & $(2.2)$ \\
\hline Diving & 5 & $(5.7)$ & 4 & (8.5) & 5 & $(4.2)$ & - & - & - & - \\
\hline Medical/surgical & 2 & $(12.8)$ & - & - & 9 & (1.6) & 4 & (6.5) & 3 & (10.9) \\
\hline Falling object & 10 & $(1.8)$ & 7 & $(1.7)$ & 6 & (3.3) & 6 & (2.8) & 5 & $(1.5)$ \\
\hline Bicycle & 10 & $(1.8)$ & - & - & 7 & $(2.8)$ & 5 & (3.6) & 4 & (2.2) \\
\hline ATV/ATC & 7 & (3.9) & 6 & $(2.5)$ & 8 & (1.8) & - & - & - & - \\
\hline Pedestrian & 8 & (3.1) & 10 & $(1.0)$ & 10 & (1.4) & 8 & (1.7) & - & - \\
\hline Other sport & 6 & $(4.2)$ & 8 & (1.5) & - & - & - & - & - & - \\
\hline Winter sports & - & - & 9 & (1.4) & - & - & - & - & - & - \\
\hline Other vehicular & - & - & - & - & - & - & 10 & (1.4) & 6 & $(1.5)$ \\
\hline Surfing & - & - & - & - & - & - & - & - & 9 & $(0.8)$ \\
\hline Other unclassified & - & - & - & - & - & - & - & - & 7 & (1.3) \\
\hline Horseback riding & - & - & - & - & - & - & 9 & (1.5) & 8 & $(0.9)$ \\
\hline Fixed-wing aircraft & - & - & - & - & - & - & - & - & 9 & $(0.8)$ \\
\hline
\end{tabular}

Note: $\mathrm{ATV} / \mathrm{ATC}=$ all-terrain vehicle/all-terrain cycle.

Table 4. Top 10 specific etiologies of spinal cord injury by sex and race

\begin{tabular}{|c|c|c|c|c|c|c|c|c|c|c|}
\hline \multirow[b]{3}{*}{ Etiology } & \multicolumn{4}{|c|}{ Sex } & \multicolumn{6}{|c|}{ Race/ethnicity } \\
\hline & \multicolumn{2}{|c|}{$\begin{array}{c}\text { Male } \\
(n=6,132)\end{array}$} & \multicolumn{2}{|c|}{$\begin{array}{c}\text { Female } \\
(n=1,700)\end{array}$} & \multicolumn{2}{|c|}{$\begin{array}{c}\text { White } \\
(n=5,051)\end{array}$} & \multicolumn{2}{|c|}{$\begin{array}{c}\text { Black } \\
(n=1,562)\end{array}$} & \multicolumn{2}{|c|}{$\begin{array}{c}\text { Hispanic } \\
(n=692)\end{array}$} \\
\hline & Rank & $(\%)$ & Rank & $(\%)$ & Rank & $(\%)$ & Rank & $(\%)$ & Rank & $(\%)$ \\
\hline Automobile & 1 & $(27.9)$ & 1 & $(44.4)$ & 1 & $(32.0)$ & 2 & $(28.9)$ & 1 & $(34.2)$ \\
\hline Fall & 2 & $(25.6)$ & 2 & $(24.2)$ & 2 & $(27.1)$ & 3 & $(19.6)$ & 2 & $(23.3)$ \\
\hline Gunshot & 3 & $(11.7)$ & 4 & $(5.8)$ & 6 & $(3.0)$ & 1 & $(33.0)$ & 3 & (14.6) \\
\hline Motorcycle & 4 & $(8.0)$ & 5 & $(2.4)$ & 3 & $(8.2)$ & 5 & $(3.4)$ & 4 & $(5.1)$ \\
\hline Diving & 5 & (5.3) & 5 & $(2.4)$ & 4 & $(5.9)$ & - & - & 6 & $(3.6)$ \\
\hline Medical/surgical & 6 & (3.3) & 3 & (7.6) & 5 & $(4.3)$ & 4 & $(3.8)$ & 5 & $(4.9)$ \\
\hline Falling object & 7 & $(2.7)$ & - & - & 8 & $(2.5)$ & 8 & $(1.2)$ & 7 & $(3.0)$ \\
\hline Bicycle & 8 & $(2.4)$ & 9 & $(1.2)$ & 7 & $(2.7)$ & - & - & 9 & (1.4) \\
\hline ATV/ATC & 9 & (1.8) & 7 & (1.6) & 9 & (2.4) & - & - & - & - \\
\hline Pedestrian & - & - & 6 & $(2.2)$ & - & - & 7 & (1.6) & 8 & $(2.3)$ \\
\hline Horseback riding & - & - & 8 & (1.5) & - & - & - & - & - & - \\
\hline Other sport & 10 & $(1.1)$ & - & - & 10 & 1.2 & - & - & - & - \\
\hline Other unclassified & - & - & - & - & - & - & 9 & $(1.0)$ & 10 & $(1.2)$ \\
\hline Other vehicular & - & - & - & - & - & - & 10 & $(0.7)$ & - & - \\
\hline Personal contact & - & - & 10 & $(1.0)$ & - & - & 6 & (2.1) & - & - \\
\hline
\end{tabular}

Note: ATV/ATC $=$ all-terrain vehicle/all-terrain cycle. 
Table 5. Day and month of injury by etiology

\begin{tabular}{|c|c|c|c|c|c|c|}
\hline \multirow[b]{2}{*}{ Characteristics } & \multicolumn{6}{|c|}{ Specific etiology, \% } \\
\hline & $\begin{array}{l}\text { Automobile } \\
(\mathrm{n}=2,465)\end{array}$ & $\begin{array}{c}\text { Fall } \\
(\mathbf{n}=1,981)\end{array}$ & $\begin{array}{c}\text { Gunshot } \\
(n=816)\end{array}$ & $\begin{array}{c}\text { Motorcycle } \\
(n=533)\end{array}$ & $\begin{array}{c}\text { Diving } \\
(\mathrm{n}=366)\end{array}$ & $\begin{array}{c}\text { Medical/surgical } \\
\quad(n=333)\end{array}$ \\
\hline \multicolumn{7}{|l|}{ Day of injury } \\
\hline Monday & 12.1 & 15.1 & 14.2 & 9.6 & 10.1 & 19.8 \\
\hline Tuesday & 11.5 & 12.7 & 12.3 & 8.8 & 6.0 & 21.0 \\
\hline Wednesday & 12.0 & 13.5 & 15.3 & 7.7 & 7.9 & 13.8 \\
\hline Thursday & 12.0 & 13.9 & 9.9 & 12.8 & 8.5 & 17.7 \\
\hline Friday & 15.2 & 14.0 & 15.1 & 11.3 & 10.9 & 15.9 \\
\hline Saturday & 18.8 & 16.6 & 17.3 & 25.3 & 27.0 & 6.3 \\
\hline Sunday & 18.5 & 14.1 & 15.9 & 24.6 & 29.5 & 5.4 \\
\hline \multicolumn{7}{|l|}{ Month of injury } \\
\hline January & 8.7 & 8.0 & 7.8 & 3.4 & 0.3 & 6.0 \\
\hline February & 6.6 & 6.9 & 5.6 & 2.6 & 1.4 & 8.7 \\
\hline March & 10.6 & 8.1 & 9.7 & 8.6 & 2.5 & 8.7 \\
\hline April & 8.6 & 8.7 & 8.3 & 11.4 & 3.6 & 11.4 \\
\hline May & 10.3 & 8.6 & 9.2 & 11.3 & 9.3 & 7.5 \\
\hline June & 7.7 & 9.1 & 9.1 & 13.1 & 23.5 & 8.7 \\
\hline July & 8.7 & 9.6 & 9.4 & 16.9 & 29.0 & 7.8 \\
\hline August & 7.1 & 9.3 & 9.3 & 9.8 & 19.1 & 6.9 \\
\hline September & 7.1 & 8.3 & 7.7 & 9.4 & 8.2 & 8.7 \\
\hline October & 8.4 & 8.1 & 8.0 & 5.8 & 2.2 & 6.0 \\
\hline November & 7.7 & 8.6 & 6.9 & 5.3 & 0.3 & 9.3 \\
\hline December & 8.6 & 6.7 & 8.9 & 2.4 & 0.8 & 10.2 \\
\hline
\end{tabular}

Table 6. Neurologic outcomes of the most common specific etiologies

\begin{tabular}{|c|c|c|c|c|c|c|}
\hline \multirow[b]{2}{*}{ Outcome } & \multicolumn{6}{|c|}{ Specific etiology, \% } \\
\hline & $\begin{array}{c}\text { Automobile } \\
(\mathrm{n}=2,394)\end{array}$ & $\begin{array}{c}\text { Fall } \\
(\mathbf{n}=1,920)\end{array}$ & $\begin{array}{c}\text { Gunshot } \\
(n=791)\end{array}$ & $\begin{array}{c}\text { Motorcycle } \\
(\mathrm{n}=512)\end{array}$ & $\begin{array}{c}\text { Diving } \\
(\mathbf{n}=361)\end{array}$ & $\begin{array}{c}\text { Medical/surgical } \\
\quad(n=309)\end{array}$ \\
\hline \multicolumn{7}{|c|}{ Level of injury } \\
\hline $\mathrm{C} 1-\mathrm{C} 4$ & 30.9 & 35.1 & 15.4 & 27.9 & 44.0 & 19.4 \\
\hline $\mathrm{C} 5-\mathrm{C} 8$ & 30.8 & 30.3 & 12.8 & 16.4 & 52.4 & 15.9 \\
\hline $\mathrm{T} 1-\mathrm{T} 6$ & 16.2 & 9.2 & 25.7 & 32.6 & 2.2 & 19.4 \\
\hline T7-S3 & 21.7 & 24.3 & 45.9 & 22.7 & 0.6 & 43.7 \\
\hline Normal & 0.5 & 1.1 & 0.3 & 0.4 & 0.8 & 1.6 \\
\hline AIS & $(\mathrm{n}=2,375)$ & $(\mathrm{n}=1,919)$ & $(n=792)$ & $(\mathrm{n}=514)$ & $(\mathrm{n}=359)$ & $(\mathrm{n}=304)$ \\
\hline A & 49.9 & 30.2 & 64.6 & 51.8 & 41.8 & 22.4 \\
\hline $\mathrm{B}$ & 13.2 & 10.7 & 10.2 & 14.6 & 30.9 & 11.8 \\
\hline $\mathrm{C}$ & 13.9 & 18.5 & 12.0 & 14.4 & 11.7 & 23.7 \\
\hline $\mathrm{D}$ & 22.7 & 39.7 & 13.0 & 18.9 & 15.0 & 40.8 \\
\hline $\mathrm{E}$ & 0.3 & 1.0 & 0.1 & 0.4 & 0.6 & 1.3 \\
\hline
\end{tabular}

Note: AIS = American Spinal Injury Association Impairment Scale. 
of gunshot wounds and motorcycle crashes resulted in a complete injury $(64.6 \%$ and $51.8 \%$, respectively).

\section{Discussion}

Demographic and injury profiles of the 7,834 persons with SCI enrolled in the NSCID and NSSCID in the past 7 years are generally consistent with previous findings from the population-based studies in the United States during the 1970s to 1990s that reported a higher SCI incidence in males, among those 16 to 30 years of age, among blacks (particularly violence-related SCIs), and during weekends and warmer months. ${ }^{6,7,9,10,16,25-27}$ The present study findings of substantial variations of specific etiologies of injury by age, sex, race/ ethnicity, day, and month further highlight the need for prevention strategies to be tailored to the targeted population and major causes of SCI to increase their impact on reducing the incidence of SCI. The strongest efforts at preventing SCI should focus on young males and automobile crashes. Prevention targeting blacks must address violence issues. Prevention programs designed for adolescents and young adults should address risktaking behaviors, whereas prevention programs for the elderly should be aimed at falls.

The observation of a strong relationship between etiologies and level/completeness of injury also provides insight regarding the mechanisms of injury, which will aid in the design of equipment and other safety measures to reduce the incidence of SCI. In addition to personal characteristics and mechanical causes, there are behavioral and environmental factors that need to be considered in the development and coordination of prevention efforts, for instance, alcohol use, seatbelt use, distracted driving, road conditions, laws and law enforcement, which are beyond the scope of this study.

\section{Limitations}

Because of the referral nature of the NSCID and NSSCID, these study results need to be interpreted with caution. The reported proportion of SCIs across different etiologies is a function of the frequency of participation in each activity as well as the risk of SCI for each activity, both of which vary substantially by personal characteristics. For example, the fact that fewer diving-related SCIs were reported among people aged 46 years or older does not necessarily suggest that diving is safer for this age group than for others. It is likely due to the fact that participation in diving activity declines substantially with advancing age. Similarly, the increase of SCIs caused by medical/surgical complications on Monday and Tuesday might simply be because more procedures are scheduled for those days than other days.

When comparing percentages across different groups, one should remember that a smaller percentage means a relatively small share compared to other entities within the group, but does not necessarily imply a lower risk. For example, automobile crashes caused $17.4 \%$ of SCIs among persons 61 years of age and older, but $38.4 \%$ for persons age 16 to 30 years. This is not likely due to a lower risk of car crashes in the older group, but rather is more likely explained by a significant portion of falls-related SCIs in the elderly so that car crashes consequently have a relatively smaller share of total injuries.

These are hospital-based cases. It is not feasible to identify appropriate denominator data to calculate actual incidence rates of SCI and estimate the risks across groups. The figures are influenced by the locations of the SCI centers that contributed data to the NSCID and NSSCID during the study period, which might not be applicable to all SCIs occurring in the United States or other countries.

\section{Conclusion}

Prevention of SCI must be multifaceted and consider personal characteristics and mechanical causes as well as the social and political context of the injury. As prevention programs likely compete for recognition of benefits and costs against other regional and national agendas and resource priorities, strategies should be aimed at the targeted population and major causes to have the greatest impact on reducing the incidence of SCI. The present study sheds light on recent statistics of the etiology of SCIs in the United States with the hope of developing and implementing costeffective prevention programs in the years to come. 


\section{Acknowledgments}

This work was supported in part by grant H133A110002 from the National Institute on Disability and Rehabilitation Research, Office of
Special Education and Rehabilitation Services, US Department of Education, Washington DC, and in part by funding from the Shriners Hospitals for Children.

\section{REFERENCES}

1. Marino RJ, Ditunno JF Jr, Donovan WH, Maynard F Jr. Neurologic recovery after traumatic spinal cord injury: data from the Model Spinal Cord Injury Systems. Arch Phys Med Rehabil. 1999;80:1391-1396

2. Fawcett JW, Curt A, Steeves JD, et al. Guidelines for the conduct of clinical trials for spinal cord injury as developed by the ICCP panel: spontaneous recovery after spinal cord injury and statistical power needed for therapeutic clinical trials. Spinal Cord. 2007;45:190205.

3. DeVivo MJ, Chen Y, Mennemeyer ST, Deutsch A. Costs of care following spinal cord injury. Top Spinal Cord Inj Rehabil. 2011 ; 16:1-9.

4. Cao Y, Chen Y, DeVivo MJ. Lifetime direct cost after spinal cord injury. Top Spinal Cord Inj Rehabil. $2011 ; 16: 10-16$.

5. Cripps RA, Lee BB, Wing P, Weerts E, Mackay J, Brown D. A global map for traumatic spinal cord injury epidemiology: towards a living data repository for injury prevention. Spinal Cord. 2011 ;49:493-501.

6. Woodruff BA, Baron RC. A description of nonfatal spinal cord injury using a hospital-based registry. Am J Prev Med. 1994;10:10-14.

7. Acton PA, Farley T, Freni LW, Ilegbodu VA, Sniezek JE, Wohlleb JC. Traumatic spinal cord injury in Arkansas, 1980 to 1989. Arch Phys Med Rehabil. 1993;74:1035-1040.

8. Virginia Department of Rehabilitation Services. Spinal Cord Injury in Virginia: A Statistical Fact Sheet. Fishersville, VA: Virginia Spinal Cord Injury System; 1993.

9. Thurman DJ, Burnett $C L$, Jeppson L, Beaudoin DE, Sniezek JE. Surveillance of spinal cord injuries in Utah, USA. Paraplegia. 1994;32:665-669.

10. Price C, Makintubee S, Herndon W, Istre GR. Epidemiology of traumatic spinal cord injury and acute hospitalization and rehabilitation charges for spinal cord injuries in Oklahoma, 1988-1990. Am J Epidemiol. 1994;139:37-47.

11. Relethford JH, Standfast SJ, Morse DL. Trends in traumatic spinal cord injury - New York, 1982-1988. MMWR Morb Mortal Wkly Rep. 1991;40:535$537,543$.

12. Colorado Department of Public Health and Environment. 1996 Annual Report of the Traumatic Spinal Cord Injury Early Notification System. Denver, CO: Colorado Department of Transportation Printing Office; 1997.

13. Bayakly AR, Lawrence DW. Spinal Cord Injury in Lovisiana 1991 Annual Report. New Orleans, LA: Louisiana Office of Public Health; 1992.
14. Johnson SC. Georgia Central Registry: Spinal Cord Disabilities and Traumatic Brain Injury. Warm Springs, GA: Roosevelt Warm Springs Institute for Rehabilitation; 1992.

15. Buechner JS, Speare MC, Fontes J. Hospitalizations for spinal cord injuries, 1994-1998. Med Health R I. 2000;83:92-93.

16. Surkin J, Gilbert BJ, Harkey HL III, Sniezek J, Currier M. Spinal cord injury in Mississippi. Findings and evaluation, 1992-1994. Spine. 2000;25:716-721.

17. Warren S, Moore M, Johnson MS. Traumatic head and spinal cord injuries in Alaska (1991-1993). Alaska Med. 1995;37:11-19.

18. DeVivo MJ. Epidemiology of traumatic spinal cord injury: trends and future implications. Spinal Cord. 2012;50:365-372.

19. National Spinal Cord Injury Statistical Center. 2011 Annual Statistical Report for the Spinal Cord Injury Model Systems. Birmingham, AL: University of Alabama at Birmingham, National Spinal Cord Injury Statistical Center; 2011. http://www.ncisc.uab.edu/ reports.aspx. Accessed October 7, 2012

20. Chen Y, Deutsch A, DeVivo MJ, et al. Current research outcomes from the spinal cord injury model systems. Arch Phys Med Rehabil. 2011 ;92:329-331.

21. Stover SL, DeVivo MJ, Go BK. History, implementation, and current status of the National Spinal Cord Injury Database. Arch Phys Med Rehabil. 1999;80:13651371.

22. Vogel LC, DeVivo MJ. Pediatric spinal cord injury issues: etiology, demographics, and pathophysiology. Top Spinal Cord Inj Rehabil. 1997;3:1-8.

23. Kirshblum SC, Burns SP, Biering-Sorensen $F$ et al. International standards for neurological classification of spinal cord injury (revised 2011). J Spinal Cord Med. 2011 ; 34:535-546.

24. DeVivo MJ, Biering-Sorensen F, New P, Chen Y. Standardization of data analysis and reporting of results from the International Spinal Cord Injury Core Data Set. Spinal Cord. 2011 ;49:596-599.

25. Bracken MB, Freeman DH Jr, Hellenbrand K. Incidence of acute traumatic hospitalized spinal cord injury in the United States, 1970-1977. Am J Epidemiol. $1981 ; 113: 615-622$.

26. Burke DA, Linden RD, Zhang YP, Maiste AC, Shields $C B$. Incidence rates and populations at risk for spinal cord injury: a regional study. Spinal Cord. $2001 ; 39: 274-278$

27. Kraus JF, Franti CE, Riggins RS, Richards D, Borhani NO. Incidence of traumatic spinal cord lesions. J Chronic Dis. 1975;28:471-492. 